University of Nebraska - Lincoln

DigitalCommons@University of Nebraska - Lincoln

Spring 3-2011

\title{
NIR-red reflectance-based algorithms for chlorophyll-a estimation in mesotrophic inland and coastal waters: Lake Kinneret case study
}

Yosef Z. Yacobi

Israel Oceanographic and Limnological Research Ltd., Kinneret Limnological Laboratory, yzy@ocean.org.il

Wesley Moses

University of Nebraska at Lincoln, wmoses.unl@gmail.com

Semion Kaganovsky

Israel Oceanographic and Limnological Research, Kinneret Limnological Laboratory, Israel

Benayahu Sulimani

Israel Oceanographic and Limnological Research, Kinneret Limnological Laboratory, Israel

Bryan Leavitt

University of Nebraska-Lincoln, bleavitt4@unl.edu

See next page for additional authors

Follow this and additional works at: https://digitalcommons.unl.edu/natrespapers

Part of the Environmental Monitoring Commons, Natural Resources and Conservation Commons, Other Earth Sciences Commons, Other Environmental Sciences Commons, and the Water Resource

Management Commons

Yacobi, Yosef Z.; Moses, Wesley; Kaganovsky, Semion; Sulimani, Benayahu; Leavitt, Bryan; and Gitelson, Anatoly A., "NIR-red reflectance-based algorithms for chlorophyll-a estimation in mesotrophic inland and coastal waters: Lake Kinneret case study" (2011). Papers in Natural Resources. 299.

https://digitalcommons.unl.edu/natrespapers/299

This Article is brought to you for free and open access by the Natural Resources, School of at DigitalCommons@University of Nebraska - Lincoln. It has been accepted for inclusion in Papers in Natural Resources by an authorized administrator of DigitalCommons@University of Nebraska - Lincoln. 
Authors

Yosef Z. Yacobi, Wesley Moses, Semion Kaganovsky, Benayahu Sulimani, Bryan Leavitt, and Anatoly A. Gitelson 


\title{
NIR-red reflectance-based algorithms for chlorophyll- $a$ estimation in mesotrophic inland and coastal waters: Lake Kinneret case study
}

\author{
Yosef Z. Yacobi, ${ }^{1}$ Wesley J. Moses, ${ }^{2}$ Semion Kaganovsky, ${ }^{1}$ \\ Benayahu Sulimani, ${ }^{1}$ Bryan C. Leavitt, ${ }^{2}$ and Anatoly A. Gitelson ${ }^{2}$ \\ 1. Israel Oceanographic and Limnological Research, Kinneret Limnological Laboratory, P.O. Box 447, Migdal \\ 14950, Israel \\ 2. CALMIT, School of Natural Resource Sciences, University of Nebraska-Lincoln, 3310 Holdredge St, Lincoln, \\ NE 68583, USA \\ Corresponding author - Y. Z. Yacobi, tel 9724672 1444, fax 9724672 4627, email yzy@ocean.org.il \\ Current address for W. J. Moses - Research Associate, The National Research Council at the Naval Research Laboratory, Wash- \\ ington, DC 20375, USA.
}

\begin{abstract}
A variety of models have been developed for estimating chlorophyll- $a$ (Chl- $a$ ) concentration in turbid and productive waters. All are based on optical information in a few spectral bands in the red and near-infra-red regions of the electromagnetic spectrum. The wavelength locations in the models used were meticulously tuned to provide the highest sensitivity to the presence of Chl- $a$ and minimal sensitivity to other constituents in water. But the caveat in these models is the need for recurrent parameterization and calibration due to changes in the biophysical characteristics of water based on the location and/or time of the year. In this study we tested the performance of NIR-red models in estimating Chl- $a$ concentrations in an environment with a range of Chl$a$ concentrations that is typical for coastal and mesotrophic inland waters. The models with the same spectral bands as MERIS, calibrated for small lakes in the Midwest U.S., were used to estimate Chl- $a$ concentration in the subtropical Lake Kinneret (Israel), where Chl- $a$ concentrations ranged from 4 to $21 \mathrm{mg} \mathrm{m}^{-3}$ during four field campaigns. A two-band model without re-parameterization was able to estimate Chl- $a$ concentration with a root mean square error less than $1.5 \mathrm{mg} \mathrm{m}^{-3}$. Our work thus indicates the potential of the model to be reliably applied without further need of parameterization and calibration based on geographical and/or seasonal regimes.
\end{abstract}

Keywords: near-infra-red, remote sensing, hyperspectral, MERIS

\section{Introduction}

Reflectance emerging from the water surface may be detected by remotely operated sensors and used for the estimation of the concentrations of chlorophyll- $a$ (Chl- $a$ ) and other constituents dissolved and suspended in water. Water quality assessment using optical sensors mounted on space-borne satellites has been proved as a fruitful method for the estimation of phytoplankton density and productivity in open seas over regional (Joint and Groom, 2000) and global (Field et al., 1998) scales. Estimation of water quality parameters by remotely operated sensors has also been applied in inland water bodies but to a lesser extent; the high variability of the composition of constituents in inland and coastal waters causes difficulties in reliable interpretation of the optical information contained in the light reflected from water surface. In open ocean wa- 
ters, where concentrations of non-algal particles and colored dissolved organic matter $(\mathrm{CDOM})$ are closely correlated with phytoplankton density, Chl- $a$ concentration is typically estimated on the basis of the reflectance in the blue and green portions of the electromagnetic spectrum (Gordon and Morel, 1983). In inland and coastal waters, most of which are turbid and productive, however, these spectral regions are of limited value in retrieving Chl- $a$ concentration because the concentrations of non-algal particles and CDOM are uncorrelated with phytoplankton concentration, and they have strong overlapping absorption features in the blue spectral region, which makes the blue reflectance an unreliable indicator of the concentration of Chl- $a$. On the other hand, the optical information in the red and the near-infra-red (NIR) regions is reliable for estimating Chl- $a$ concentration in turbid productive waters, as the absorption effects of non-algal particles and CDOM largely fade in those portions of the electromagnetic spectrum (e.g., Gitelson, 1992; Gons, 1999; Schalles, 2006).

A variety of algorithms have been developed for retrieving Chl- $a$ concentration in turbid productive waters based on the optical information in the red and NIR regions acquired at water level. These include the ratio of the reflectance peak near $700 \mathrm{~nm}$ in the NIR region to the reflectance at $670 \mathrm{~nm}$ in the red region (Chl- $a$ absorption peak), the ratio R705/R670 (Gitelson, 1992; Dekker, 1993; Han and Rundquist, 1997), and the position of the NIR reflectance peak (Gitelson, 1992). Using vector analysis, Stumpf and Tyler (1988) showed that the ratio of reflectances in the NIR and the red bands of space-borne sensors, such as AVHRR (Advanced Very High Resolution Radiometer) and CZCS (Coastal Zone Color Scanner), can be used to identify phytoplankton blooms and estimate Chl- $a$ concentrations above $10 \mathrm{mg} \mathrm{m}^{-3}$ in turbid estuaries. Gons (1999) used the ratio of reflectances at $704 \mathrm{~nm}$ and $672 \mathrm{~nm}$ as well as the reflectance at $775 \mathrm{~nm}$ to construct an algorithm for assessing a wide range of Chl- $a$ concentrations. Gons et al. $(2002,2005)$ adapted this algorithm for use with MERIS (MEdium Resolution Imaging Spectrometer) satellite imagery by using reflectances at $708 \mathrm{~nm}, 665 \mathrm{~nm}$, and $778 \mathrm{~nm}$ instead of the original bands and reported highly accurate estimates of Chl- $a$ concentration retrieved from MERIS images. Close correlations between Chl- $a$ concentrations and three-band combinations (Hoge et al., 1987; Yacobi et al., 1995; Pierson and Strombeck, 2000) and even a four-band combination (Le et al., 2009) in the red and NIR regions have been reported.

Previous work showed that NIR-red algorithms based on a conceptual, semi-analytical model for pigment retrieval in optically deep media can provide accurate satellite-derived estimates of pigment concentrations in turbid productive waters (Dall'Olmo et al., 2003; Dall'Olmo and Gitelson, 2005; Gitelson et al., 2008). The model was formulated as follows:

$$
\text { Chl- } a=\left[R^{-1}\left(\lambda_{1}\right)-R^{-1}\left(\lambda_{2}\right)\right] \times R\left(\lambda_{3}\right)
$$

where $R\left(\lambda_{1}\right), R\left(\lambda_{2}\right)$, and $R\left(\lambda_{3}\right)$ are the reflectance values at wavelengths $\lambda_{1}, \lambda_{2}$, and $\lambda_{3}$, respectively. $\lambda_{1}$ is in a spectral region such that $R\left(\lambda_{1}\right)$ is maximally sensitive to absorption by Chl-a. $\lambda_{2}$ is in a spectral region such that $R\left(\lambda_{2}\right)$ is minimally sensitive to absorption by Chl- $a$ and its sensitivity to absorption by other constituents is comparable to that of $R\left(\lambda_{1}\right) \cdot \lambda_{3}$ is located in a spectral region such that $R\left(\lambda_{3}\right)$ is minimally af- fected by absorption due to any constituent, and is therefore used to account for the variability in scattering amongst water samples.

For waters that do not have significant concentrations of non-algal particles and CDOM, the subtraction of $R^{-1}\left(\lambda_{2}\right)$ in the model may be omitted (Dall'Olmo and Gitelson, 2005), leading to a special case of two-band NIR-red model (Stumpf and Tyler, 1988):

$$
\text { Chl- } a R^{-1}\left(\lambda_{1}\right) \times R\left(\lambda_{3}\right)
$$

where $\lambda_{1}$ is in the red region while $\lambda_{3}$ in the NIR region beyond $730 \mathrm{~nm}$.

Another two-band model, which is different in its formulation from the previously mentioned two-band model is (Gitelson, 1992):

$$
\text { Chl-a } R^{-1}\left(\lambda_{1}\right) \times R\left(\lambda_{2}\right)
$$

where $\lambda_{1}$ is in the red region and $\lambda_{2}$ is in the region of the reflectance peak around $700-710 \mathrm{~nm}$.

The accuracy of algorithms, developed on the basis of Eqs. (1) and (3)(1) and (3) and optical information acquired from water at surface level, was evaluated with spectral bands available on MERIS and proven to be a reliable tool for turbid productive waters with $\mathrm{Chl}-a$ concentrations in the range 2-83 $\mathrm{mg} \mathrm{m}^{-3}$ (Gitelson et al., 2009).

The goal of the current study was to test the applicability of the NIR-red algorithms, based on MERIS and MODIS (MODerate resolution Imaging Spectroradiometer) spectral bands, in an aquatic environment that is characterized by a range of Chl- $a$ concentrations (less than $25 \mathrm{mg} \mathrm{m}^{-3}$ ) typical for coastal and mesotrophic inland waters.

\section{Material and methods}

Data presented in the current study were acquired in four campaigns on Lake Kinneret, Israel, in May and June 2009, totaling 56 samplings. Lake Kinneret is a warm, monomictic lake with a surface area of $164 \mathrm{~km}^{2}$, average volume of $4100 \mathrm{~mm}^{3}$, and an average annual recharge of about $450 \mathrm{~mm}^{3}$. The mean and maximum depths are $23 \mathrm{~m}$ and $43 \mathrm{~m}$, respectively, when the mean lake level is $209 \mathrm{~m}$ below sea level. The work was done in the pelagic region, where water depth was $>10 \mathrm{~m}$ and the stations were unlikely to be influenced by bottom reflectance, considering the lake water transparency (Yacobi, 2006).

\subsection{Acquisition of data in the lake} disk.

Secchi depth was measured by the aid of a $25-\mathrm{cm}$ white

Hyperspectral reflectance measurements were taken from a boat using two intercalibrated Ocean Optics ${ }^{\circledR}$ USB2000 radiometers, each with a coupled 2048-element linear CCD-array detector. Data were collected in the range $400-900 \mathrm{~nm}$ with a sampling interval of $0.3 \mathrm{~nm}$, spectral resolution of $1.5 \mathrm{~nm}$, and signal-to-noise ratio above 250 . Radiometer 1 , equipped with a $25^{\circ}$ field-of-view optical fiber, was pointed downward to measure the below-surface upwelling radiance, $L_{\text {up }}(\lambda)$, at na- 
dir. The tip of the optical fiber was kept just below the water surface by means of a 2-m long, hand-held dark pole. To simultaneously measure incident irradiance $E_{\text {inc }}(\lambda)$, radiometer 2 , connected to an optical fiber fitted with a cosine collector, was pointed upward and mounted on top of a $2.5 \mathrm{~m}$ tall mast. To match the transfer functions of the radiometers, intercalibration of the instruments was accomplished by measuring simultaneously the upwelling radiance $L_{\text {cal }}(\lambda)$ from a white Spectralon ${ }^{\circledR}$ reflectance standard (from Labsphere, Inc., North Sutton, $\mathrm{NH}$ ) with known reflectance $R_{\text {cal }}(\lambda)$, and the corresponding incident irradiance $E_{\text {cal }}(\lambda)$. The remote sensing reflectance at nadir was computed as:

$$
R_{\mathrm{rs}}(\lambda)=\left[\frac{L_{\mathrm{up}}(\lambda)}{E_{\mathrm{inc}}(\lambda)} \times \frac{E_{\mathrm{cal}}(\lambda)}{L_{\mathrm{cal}}(\lambda)} \times 100 \times R_{\mathrm{cal}}(\lambda) \times \frac{t}{n^{2}} \times \frac{F(\lambda)}{\pi}\right]
$$

where $\pi$ is used to transform the irradiance reflectance into remote sensing reflectance, $n$ is the refractive index of water relative to air (taken as equal to 1.33), $F(\lambda)$ is the spectral immersion factor computed after Ohde and Siegel (2003), and $t$ is the water-to-air transmittance (taken as equal to 0.98 ).

To simulate surface reflectances in satellite spectral bands, measured reflectances were averaged in the spectral bands of MODIS: band 13: 662-672 nm, and band 15: 743-753 nm, and MERIS: band 7: 660-670 nm, band 9: 703-713 nm, and band 10: 748-755.5 nm.

The NIR-red models were used in the following forms: Two-Band MODIS NIR-red model based on (Equation (2))

$$
\text { Chl- } a\left(R_{\text {band 13 }}\right)^{-1} \times\left(R_{\text {band 15 }}\right)
$$

Three-band MERIS NIR-red model based on (Equation (1)):

$$
\text { Chl- } a\left[\left(R_{\text {band } 7}\right)^{-1}-\left(R_{\text {band } 9}\right)^{-1}\right] \times\left(R_{\text {band10 }}\right)
$$

Two-Band MERIS NIR-red Model based on (Equation (3)):

$$
\text { Chl- } a\left(R_{\text {band } 7}\right)^{-1} \times\left(R_{\text {band } 9}\right)
$$

\subsection{Laboratory analysis}

Water samples collected at each station were processed in the laboratory within $1 \mathrm{~h}$ after collection. The samples were filtered onto glass-fiber filters (Whatman GF/F), extracted in $90 \%$ acetone, and left overnight at $4{ }^{\circ} \mathrm{C}$ in the dark. Chl- $a$ concentration was determined fluorometrically (Holm-Hansen et al., 1965), following clarification of the extract by centrifugation for $3 \mathrm{~min}$ at $1100 \mathrm{~g}$. The concentration of total suspended solids (TSS) was determined by filtering a known volume of water sample onto GF/F filters and drying the filters for $24 \mathrm{~h}$ at $105^{\circ} \mathrm{C}$. Organic matter content (OMC) of the particulate material was measured as the component lost by ignition, i.e., following combustion at $530{ }^{\circ} \mathrm{C}$; carbon content was assumed to be $50 \%$ of OMC (Eckert and Parparov, 2006).

\section{Results}

Chl- $a$ concentration ranged from 4.6 to $20.8 \mathrm{mg} \mathrm{m}^{-3}$ and TSS from 3.3 to $5.6 \mathrm{~g} \mathrm{~m}^{-3}$. Organic matter comprised $62-85 \%$ of suspended particles. The temporal variation of Chl- $a$ concentration in Lake Kinneret was far below the expected variation based on the multi-annual record of the lake (Yacobi, 2006). The decline of temporal variation is also paralleled by the decline of spatial variability of Chl- $a$ concentration. Phytoplankton was dominated by mostly small species of cyanophytes, diatoms, chlorophytes, and dinoflagellates in varying proportions throughout the May-June period when the study was conducted. High phytoplankton density in the lake is mostly affiliated with the presence of the large dinoflagellate Peridinium gatunense, which displays a conspicuous patchy distribution, with a difference of two orders of magnitude between the lowest and highest densities. However, Peridinium did not develop dense populations in 2009 and small forms dominated phytoplankton. Chl- $a$ showed a weakly linear correlation with TSS, with $r^{2}=0.49(n=31$, $p<0.001)$. Secchi depth ranged from 1.7 to $3.9 \mathrm{~m}$ and was nonlinearly correlated with Chl- $a\left(r^{2}=0.57, n=56, p<0.001\right)$. These relationships demonstrate that the samples were collected from a meso-eutrophic, case 2 water body.

\subsection{Prominent features of the reflectance spectra}

All reflectance spectra collected in this study had a similar shape, although with wide variations in magnitude (Figure 1). Reciprocal of reflectance, which is a proxy of absorption coefficient (Gordon et al., 1975), demonstrates the unique effects of optically active constituents (Figure 2) and highlights the effect of water absorption at wavelengths longer than $600 \mathrm{~nm}$, especially beyond $690 \mathrm{~nm}$, where there is a rapid increase in absorption by water. Peaks and troughs can be clearly seen in the reciprocal reflectance spectra shown in Figure 2. Total absorption coefficient was high in the blue range of the spectrum with a conspicuous peak at $440 \mathrm{~nm}$, which was followed by a smooth decline to a prominent trough in the green region, with minor changes in slope at $492 \mathrm{~nm}, 515 \mathrm{~nm}$, and $551 \mathrm{~nm}$. A minimum in absorption coefficient was seen in the green region around $560 \mathrm{~nm}$. The minimum was followed by a mild increase until about $650 \mathrm{~nm}$ due to increase in water absorption (Figure 2). The main features in the red region are a peak around $670 \mathrm{~nm}$ due to Chl- $a$ absorption and a prominent minimum of the reciprocal reflectance around $700 \mathrm{~nm}$. This minimum is caused by the combination of decreasing absorption by Chl- $a$ and increasing absorption by water; it corresponds to a peak in reflectance (Figure 1).

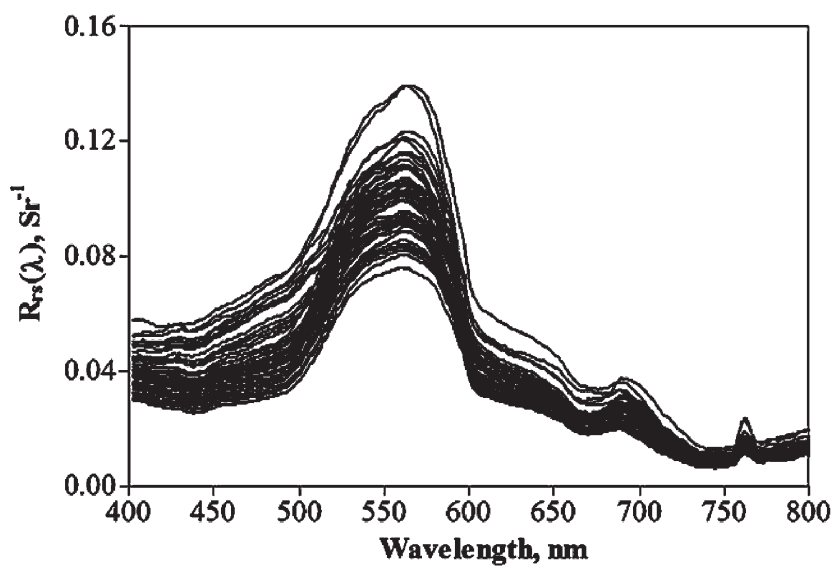

Figure 1. Reflectance spectra acquired in Lake Kinneret from May throughout June 2009. 


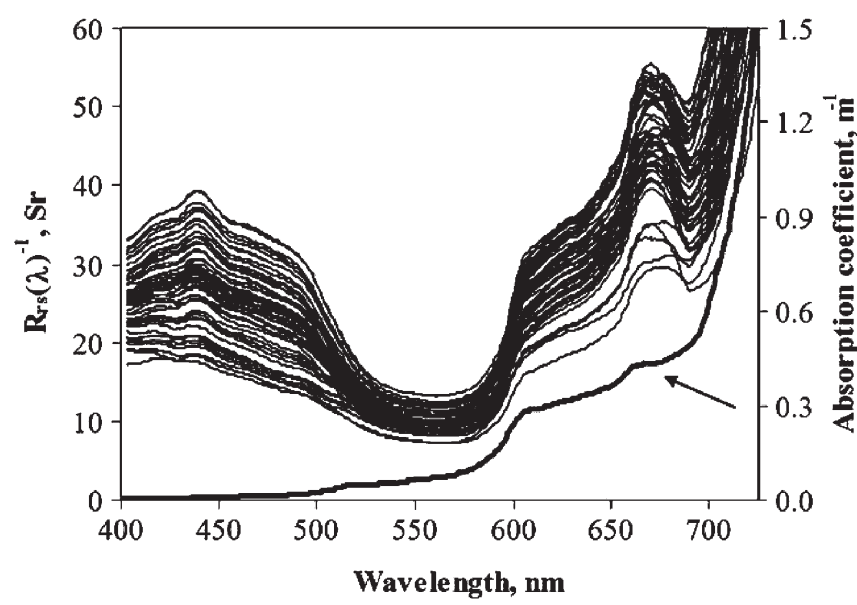

Figure 2. Reciprocal reflectance spectra acquired in Lake Kinneret from May throughout June 2009, and absorption of pure water (solid line, indicated by an arrow).

\subsection{Performance of the NIR-red models}

The optimal spectral bands in the models - Equations (1) and (3)-might vary for water bodies with different optical properties, and an optimization technique should be employed in order to refine the choice of wavelengths $\lambda_{1}, \lambda_{2}$, and $\lambda_{3}$ (Dall'Olmo and Gitelson, 2005). To find the positions of optimal wavelengths for our data set, we calculated spectra of the root mean square error (RMSE) of Chl- $a$ concentration estimation for $\lambda_{1}, \lambda_{2}$, and $\lambda_{3}$ using techniques suggested in Dall'Olmo and Gitelson (2005) - Figure 3. The lowest RMSE for $\lambda_{2}$ was found around $702 \mathrm{~nm}$ whereas the lowest RMSE for $\lambda_{3}$ occurred in a wide range from 710 to $760 \mathrm{~nm}$ with minimal values near 713 nm (Figure 3a). The lowest RMSE values for $\lambda_{1}$ appeared to occur in the range 660 to $670 \mathrm{~nm}$ with a definite minimum at $665 \mathrm{~nm}$ (Figure 3b). A decrease in RMSE values for $\lambda_{1}$ was also observed in the range from of 420 to $490 \mathrm{~nm}$, but the values were not as low as those observed in the red region.

Two important points are: (i) the positions of optimal wavelengths coincided with those found for lakes in the Midwest U.S. and in the Chesapeake Bay (Dall'Olmo and Gitelson, 2005; Gitelson et al., 2008, 2009) and (ii) all three MERIS spectral bands corresponded to spectral regions of minimal RMSE values (shadowed areas in Figure 3 for MERIS bands 7, 9 and 10).

Reciprocal reflectance at $665 \mathrm{~nm}$, where absorption by Chl$a$ is maximal, was virtually independent of Chl- $a$ concentration (Figure 4a). It shows that other factors strongly affect the reflectance in this spectral region (e.g., scattering by suspended matter and absorption by CDOM among others). Subtraction of the reciprocal reflectance at $708 \mathrm{~nm}$ from the reciprocal reflectance at $665 \mathrm{~nm}$, the first term in the three-band model (Equation (1)), resulted in the removal of most of these effects, as $\left(R_{665}^{-1}-R_{708}^{-1}\right)$ was positively correlated with Chl- $a$ concentration, with $r^{2}>0.86$ (Figure $4 \mathrm{~b}$ ), though affected by scattering by inorganic particles. Multiplication of $\left(R_{665}^{-1}-R_{708}^{-1}\right)$ by the reflectance at $753 \mathrm{~nm}$, as in the three-band model (Equation (1)), significantly minimized the effect of scattering by inorganic particles and resulted in a closer relationship with Chl- $a$ concentration, with $r^{2}>0.93$ (Figure 4c). A two-band
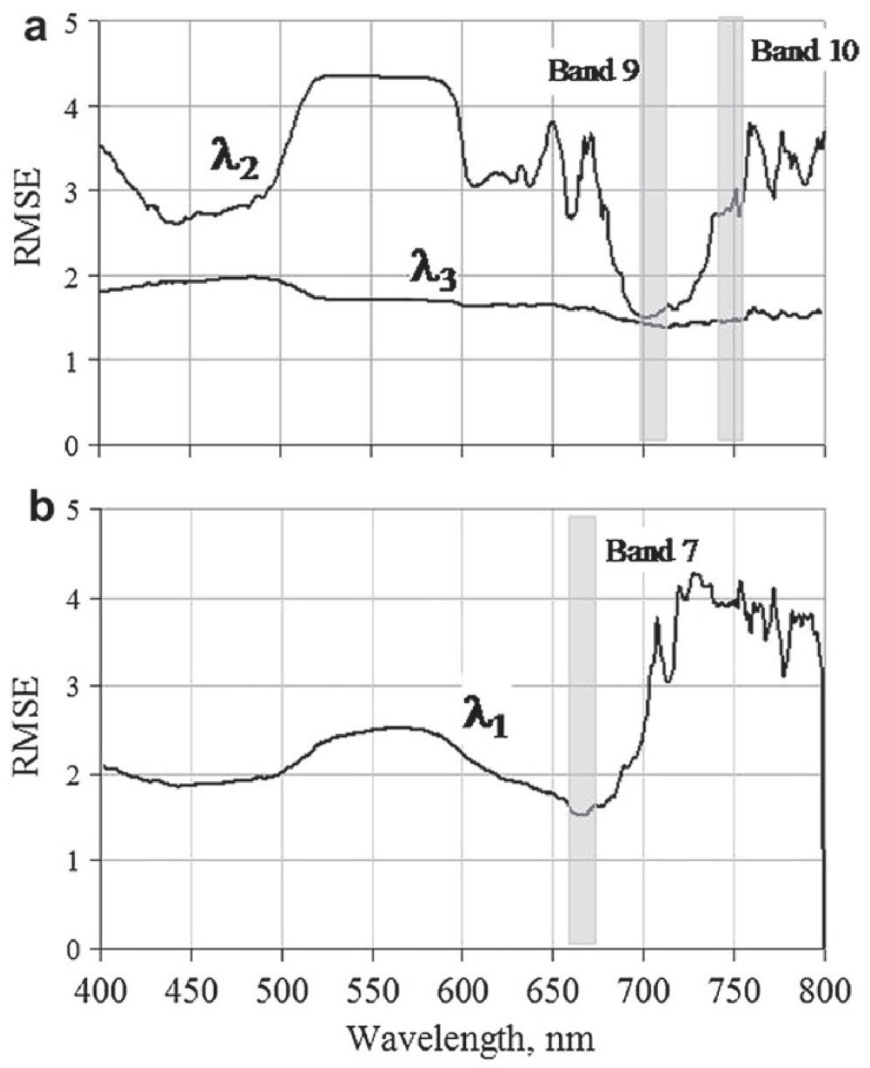

Figure 3. Spectra of root mean square error (RMSE) of the linear relationship between Chl- $a$ concentration and 3-band NIR-red model [Equation (1)]: (a) $\lambda_{2}$ is the wavelength where the reflectance is minimally sensitive to absorption by Chl- $a$ and $\lambda_{3}$ is the wavelength where the reflectance is minimally sensitive to absorption by all suspended and dissolved constituents in water; (b) $\lambda_{1}$ is the wavelength where the reflectance is maximally sensitive to absorption by Chl- $a$. Shaded areas delineate the wavebands which correspond (from left to right) to MERIS bands 7, 9 and 10 .

model (Equation (3)), widely used for Chl- $a$ estimation (Gitelson, 1992), was also accurate $\left(r^{2}>0.94\right)$ (Figure $\left.4 \mathrm{~d}\right)$. Thus, both the three-band (Equation (1), Figure 4c) and the two-band (Equation (3), Figure 4d) models had close relationships with Chl- $a$ concentration, with high correlation coefficients. In all cases a non-linear regression produced a better fit than a linear regression, but the latter still yielded high values of correlation coefficient.

The two-band MODIS NIR-red model (Equation (5)), which was based on the approach of Stumpf and Tyler (1988), yielded a moderate correlation with Chl- $a$ concentration $\left(r^{2}=0.52\right.$, Figure $5 \mathrm{a}$ ). Due to the merely moderate correlation of the twoband MODIS NIR-red model with Chl- $a$ concentrations and its general inability to accurately estimate low-to-moderate Chla concentrations (Moses et al., 2009a), no attempt was made to calibrate this model or do further assessment of its accuracy in estimating Chl- $a$ concentration.

The three-band (Equation (6)) and two-band (Equation (7)) NIR-red models with simulated MERIS bands yielded very high correlations with Chl- $a$ concentration, with quadratic polynomial best fit functions (Figure $5 b, c)$. The linear relationships between the model values and Chl- $a$ concentrations 

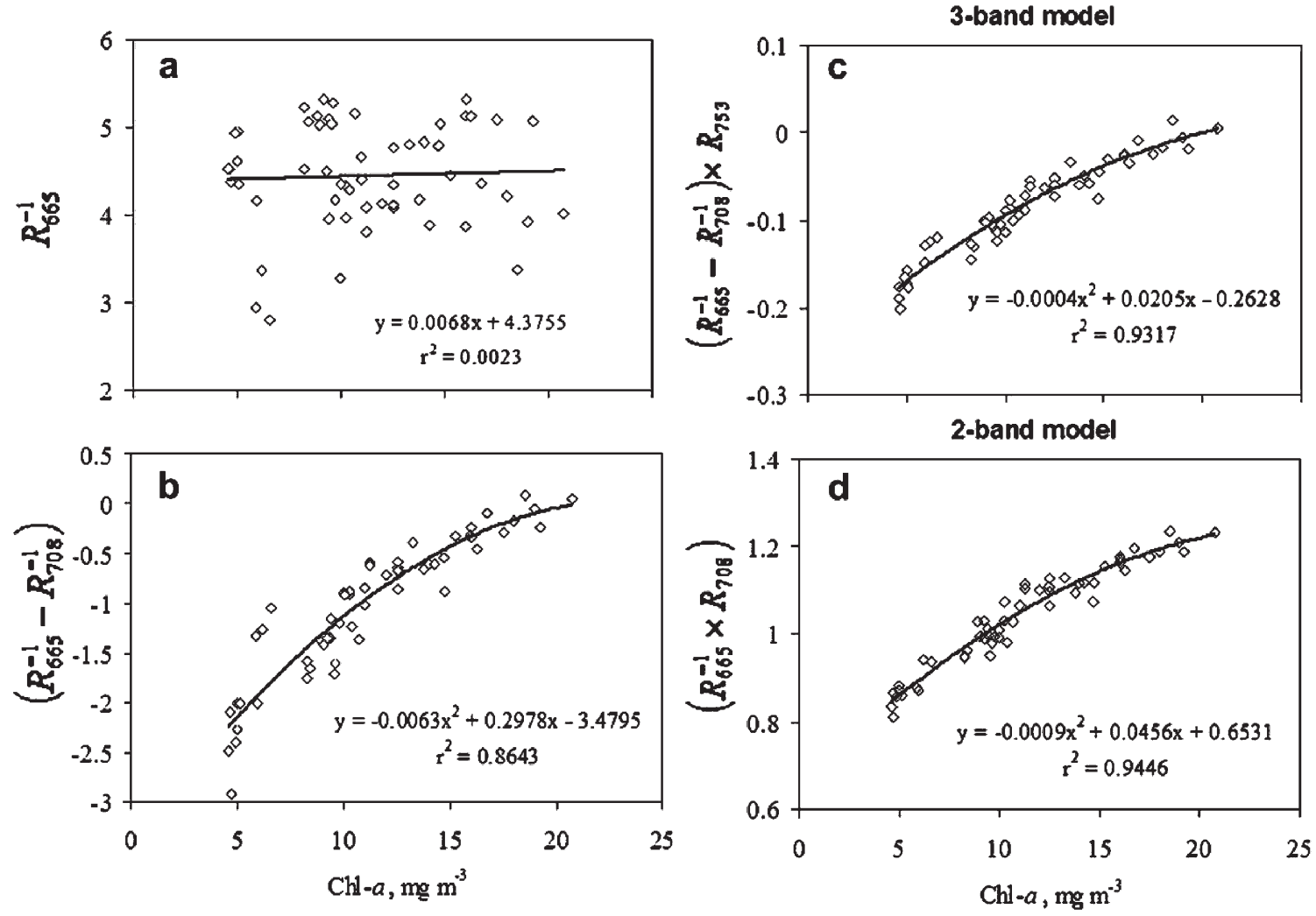

Figure 4. Models with narrow spectral bands plotted versus Chl- $a$ concentration: (a) Reciprocal reflectance at $665 \mathrm{~nm}$, (b) The difference of reciprocal reflectances at 665 and $708 \mathrm{~nm}$; (c) Three-band model based on the reflectance at 665, 708 and $753 \mathrm{~nm}$; (d) Two-band model (Equation (3)) with wavelengths $708 \mathrm{~nm}$ and $665 \mathrm{~nm}$.

were as follows:

$$
\begin{aligned}
& \text { Chl- } a=80.167 \times(3 \text {-band model })+17.105 \\
& \text { Chl- } a=41.127 \times(2 \text {-band model })-23.484
\end{aligned}
$$

The MERIS-based three-band and two-band NIR-red models were previously parameterized and calibrated in small and shallow lakes in Nebraska, USA, where Chl- $a$ concentrations ranged from 2 to $200 \mathrm{mg} \mathrm{m}^{-3}$ (Gitelson et al., 2009). For Chla concentrations not surpassing $25 \mathrm{mg} \mathrm{m}^{-3}$, the relationships between the models and Chl- $a$ concentration for the Nebraska lakes dataset were as follows:

$$
\begin{gathered}
\text { Chl }=142.27 \times(3 \text {-band model })+19.516 \\
\text { Chl }=45.535 \times(2 \text {-band model })-25.895
\end{gathered}
$$

As can be seen, the coefficients of Equation (9) for the twoband NIR-red model is similar to the model calibrated using data from Nebraska lakes, Equation (11).

We applied the two-band and three-band algorithms calibrated using Nebraska lakes data (Equations (10) and (11)) to the data collected in Lake Kinneret. The results of this validation test are presented in Figure 6. For the two-band model, the relationship between the estimated $\left(\mathrm{Chl}_{\text {est }}\right)$ and measured $\mathrm{Chl}\left(\mathrm{Chl}_{\text {meas }}\right)$ concentrations was:

$$
\mathrm{Chl}_{\text {est }}=0.985 \mathrm{Chl}_{\text {meas }}+0.6814
$$

with the RMSE of the estimated Chl- $a$ concentration less than $1.25 \mathrm{mg} \mathrm{m}^{-3}$ and the mean normalized bias below $5.5 \%$ (Figure 6a).

For the three-band model, the relationship was

$$
\mathrm{Chl}_{\text {pred }}=1.386 \mathrm{Chl}_{\text {meas }}-5.0202
$$

with an RMSE of $2.61 \mathrm{mg} \mathrm{m}^{-3}$ and the mean normalized bias below $46 \%$ (Figure 6b).

While the two-band algorithm calibrated in Nebraska was very accurate in estimating Chl- $a$ concentrations over the entire range in Lake Kinneret (Figure 6c), the three-band algorithm was accurate only for Chl- $a$ concentrations above $10 \mathrm{mg} \mathrm{m}^{-3}$ and exhibited a significant underestimation at lower Chl- $a$ concentrations (Figure $6 \mathrm{~d}$ ).

\section{Discussion}

\subsection{Optical effect of water constituents}

Seldom are pigment features as clearly evident in reflectance spectra as seen in our study. That is particularly the case in productive waters, where non-pigmented particles and 

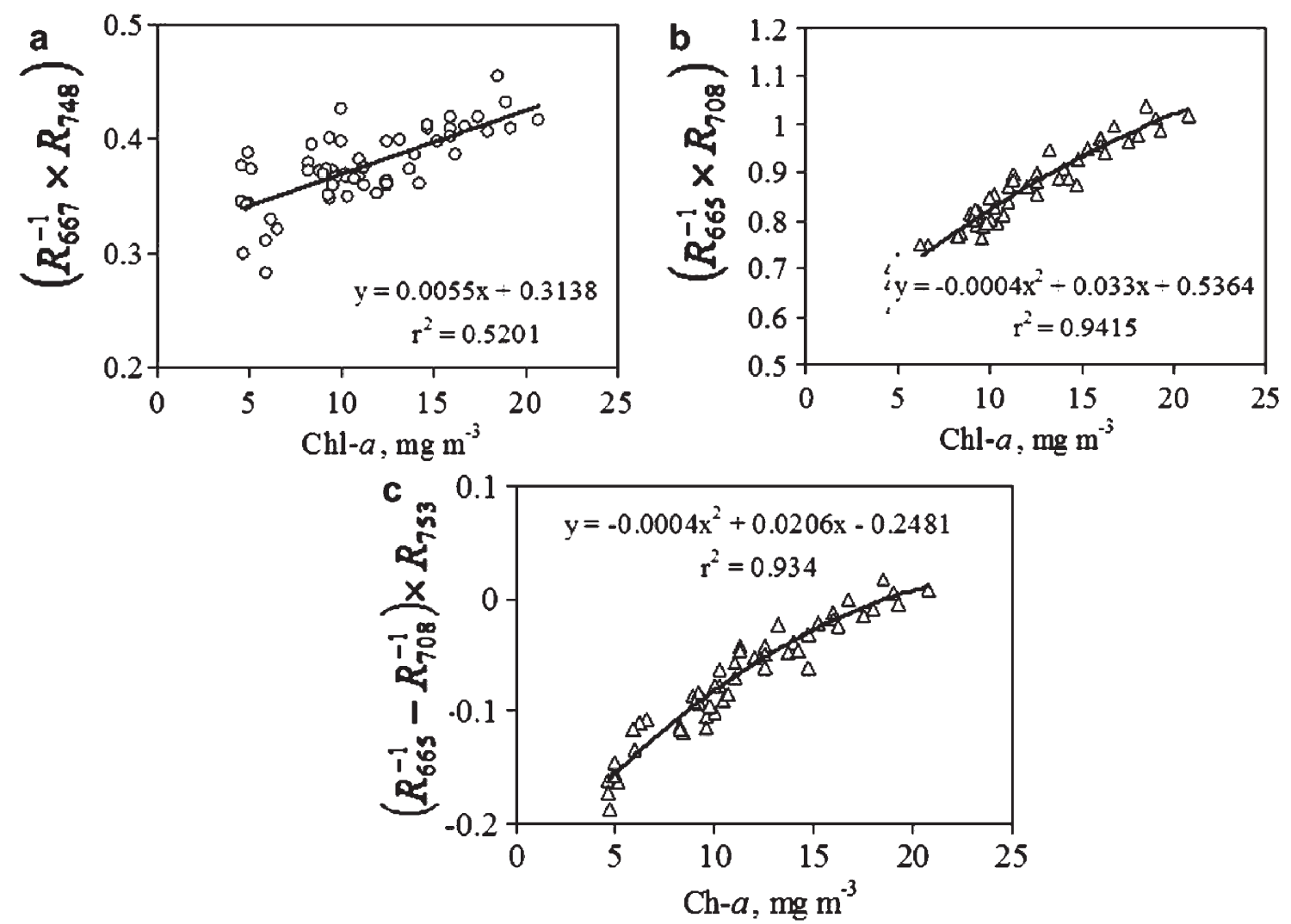

Figure 5. NIR-Red models with simulated bands of the space-borne sensors plotted versus Chl- $a$ concentration: (a) two-band MODIS NIR-red model (Equation (5)); (b) two-band MERIS NIR-red model (Equation (7)); (c) three-band MERIS NIR-red MERIS model (Equation (6)).

CDOM mask the pigment signature in the blue range of the electromagnetic spectrum (e.g., Dekker, 1993; Schalles, 2006). The troughs at $440 \mathrm{~nm}$ and $670 \mathrm{~nm}$ are formed by Chl- $a$ absorption, and the prominent peak around $560 \mathrm{~nm}$ is an outcome of minimum absorption by all pigments. Although the optical signature of Chl- $a$ around $670 \mathrm{~nm}$ is clearly identified in all but the most oligotrophic waters (Schalles, 2006), the appearance of a trough around $440 \mathrm{~nm}$, is not common in spectra acquired in productive coastal and inland waters. The optical activity of detritus and CDOM declines exponentially from $400 \mathrm{~nm}$ towards longer wavelengths, but in productive water is often high enough to mask pigment absorption (Gege and Albert, 2006). The effect of the absorption of CDOM on reflectance is often a major factor that renders the blue range of the electromagnetic spectrum ineffective for use in estimating Chla concentration in productive waters. But, CDOM concentration in Lake Kinneret during the time period of the reported study was extremely small (absorption coefficient of filtrate passing through a $0.45 \mu \mathrm{m}$ filter at $440 \mathrm{~nm}$, was $<0.06 \mathrm{~m}^{-1}$ ). Therefore, only detritus was the potential component to interfere with pigment absorption. Subtracting the concentration of organic matter (OM) harbored by phytoplankton from the total OM, we estimate that the concentration of non-algal OM during our study was, on average, less than $1.6 \mathrm{~g} \mathrm{~m}^{-3}$. Even if all non-algal OM is considered as detritus, we assume that the relatively low concentration was not high enough to mask the absorption signature of phytoplankton, and the small variation in detritus concentration was not sufficient to modify the impact of pigments on the reflectance spectra. The spectral fea- ture at 514-515 $\mathrm{nm}$ is probably the imprint of the absorption of fucoxanthin and peridinin, harbored by diatoms and dinoflagellates, respectively. These carotenoids have a maximum absorption in solution at around $470 \mathrm{~nm}$ and the assumption is that the shift in vivo is $40 \mathrm{~nm}$ (Bidigare et al., 1990). Thus, the impact of the presence of diatoms and dinoflagellates should peak at around $510 \mathrm{~nm}$.

\subsection{The optimal NIR-red model for estimating Chl-a concentration}

We tested several other NIR-red models, to which references were made in the Introduction section, on our dataset, and found that most of them can give reasonably accurate estimates of Chl- $a$ concentration. However, the correlation coefficients for the regression between the estimates from the aforementioned models and measured Chl- $a$ concentrations were mostly not higher than $0.6-0.7$, which is significantly lower than those achieved for the MERIS-based two-band and three-band NIR-red models. An exception was the model suggested by Gons et al. $(2002,2005)$. The estimates from this model, which is based on the ratio $R_{708} / R_{665}$, were highly correlated with Chl- $a\left(r^{2}>0.93\right)$. However, in addition to the ratio $R_{708} / R_{665}$, Gons' model involves reflectance in NIR region at $778 \mathrm{~nm}$, which is in the region of very high water absorption and, thus, very low reflectance. Hence, while performing well for data taken with field spectrometers at water surface level, this model is quite susceptible to effects arising from low signal-to-noise ratio in the detector and residual effects from at- 

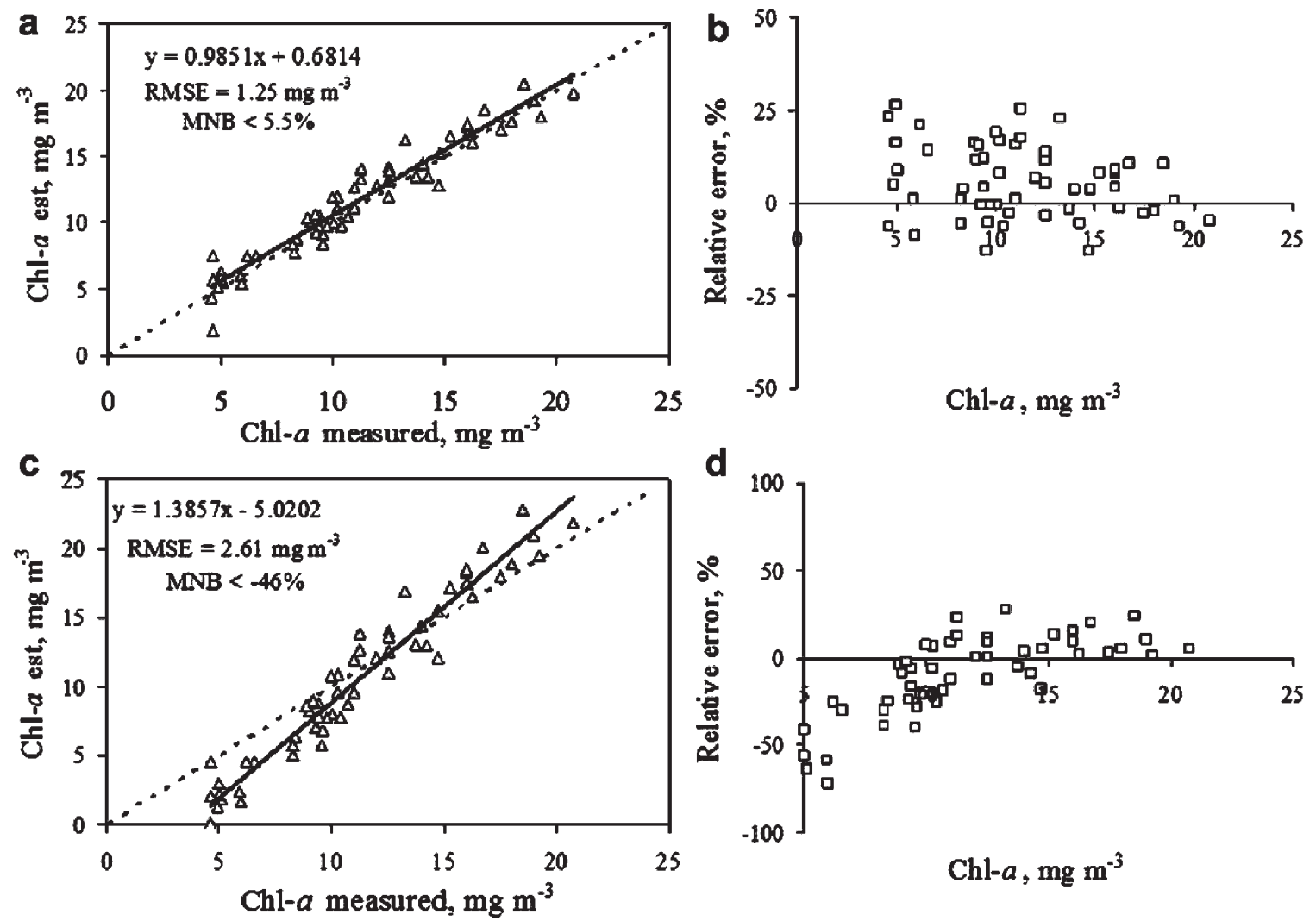

Figure 6. Comparison of Chl- $a$ concentration determined in laboratory and Chl- $a$ concentration estimated using NIR-red models calibrated in Fremont Lakes, NE: (a) the two-band NIR-red model (Equation 11), and (b) the three-band NIR-red model (Equation 10), with the 1-by-1 line (dashed line) and the best fit function (solid line). The relative errors of Chl- $a$ estimation by the (c) two-band and (d) three-band models are also shown.

mospheric correction when applied to satellite data, whereas the two-band model-Equation (3) - is not affected by these factors to the same degree.

While the MERIS-based two-band NIR-red model gave consistently highly accurate estimates over the entire range of Chl- $a$ concentrations in our dataset, the three-band NIR-red model yielded less accurate estimates for Chl- $a$ concentrations less than $10 \mathrm{mg} \mathrm{m}^{-3}$. The three-band model, which involves the use of information acquired at $\lambda_{3}$ to remove the effects of particulate backscattering, is theoretically robust. However, it relies on the assumption of spectral uniformity of backscattering coefficient over the entire range of wavelengths $\left(\lambda_{1}-\lambda_{3}\right)$, thus, between 660 and $750 \mathrm{~nm}$. Such an assumption may be invalid for inland waters (Gons, 1999; Oki and Yasuoka, 2002). Moreover, there are also documented instances of non-uniform backscattering in the visible and NIR regions and evidences that the pattern of this non-uniformity might vary across water bodies (Herlevi, 2002; Kutser et al., 2009; Aas et al., 2005). The effects of such non-uniformity in backscattering coefficient will have a higher impact on the accuracy of the three-band model at low Chl- $a$ concentrations. Moreover, with the two-band model spanning a lower range of wavelengths than the three-band model, the effects of the spectral non-uniformity of backscattering will be less pronounced in the twoband model. We, therefore, postulate that the spectral nonuniformity of backscattering coefficient is a primary factor that caused the MERIS-based three-band NIR-red model to be less accurate than the MERIS-based two-band NIR-red model at Chl- $a$ concentrations lower than $10 \mathrm{mg} \mathrm{m}^{-3}$. Thus, the MERISbased two-band NIR-red model seems to be the most optimal model for estimating low-to-moderate Chl- $a$ concentrations in turbid productive waters such as Lake Kinneret.

\section{Conclusions}

The reflectance spectra in the dataset were relatively uniform, i.e., the location of peaks and troughs showed only minor shifts with changes in Chl- $a$ concentration. The MERISbased NIR-red models had a consistent close correlation with Chl- $a$ concentration. The rationale behind the waveband choice for the construction of NIR-red algorithms for turbid productive waters have been outlined in a recent review (Gitelson et al., 2011), and tested in several campaigns in different water bodies (Gitelson et al., 2008, 2009; Moses et al., 2009a). The MERIS-based NIR-red algorithms developed, parameterized, and calibrated for lakes in Nebraska, were reliable for estimating Chl- $a$ concentration in Lake Kinneret. Similar results were obtained when the algorithms calibrated for lakes in Nebraska were used to estimate Chl- $a$ concentrations in the Azov Sea, Russia, using actual MERIS data (Moses et al., 2009b) and when they were applied to reflectances simulated by the radiative transfer model, Hydrolight (Gilerson et al., 2010). This strongly suggests that the MERIS-based NIR-red algorithms, 
especially the two-band NIR-red algorithm, do not need to be re-parameterized for waters with varying biophysical characteristics, and have a strong potential for being applied universally for turbid productive waters around the globe. Our study shows the robustness of the MERIS-based NIR-red algorithms at low-to-moderate $\mathrm{Chl}-a$ concentrations, which are typical for mesotrophic waters around the globe. However, further tests need to be done to validate the universal applicability of these algorithms for inland and coastal waters.

Acknowledgments - We would like to thank skipper Moti Diamant for his reliable partnership in the execution of our lake missions. We gratefully acknowledge the use of radiometers provided by the Center for Advanced Land Management Information Technologies (CALMIT), University of Nebraska-Lincoln. We acknowledge the contribution of three anonymous reviewers for Water Research who provided constructive criticisms that helped to improve the clarity and quality of the presentation. This work was partially supported by the Lake Kinneret Extended Monitoring Program, funded by the Israeli Water Authority.

\section{References}

Aas et al., 2005 - E. Aas, J. Høkedal, and K. Sørensen, Spectral backscattering coefficient in coastal waters, Int. J. Remote Sens 26 (2005), pp. 331-343.

Bidigare et al., 1990 - R. R. Bidigare, M. E. Ondrusek, J. H. Morrow, and D. A. Kiefer, In vivo absorption properties of algal pigments, SPIE 1302 (1990), pp. 290-302 Ocean Optics X.

Dall'Olmo and Gitelson, 2005 - G. Dall'Olmo and A. A. Gitelson, Effect of bio-optical parameter variability on the remote estimation of chlorophyll- $a$ concentration in turbid productive waters: experimental results, Appl. Opt. 44 (2005), pp. 412-422 see also Erratum, Appl. Opt., 44, 3342.

Dall'Olmo et al., 2003 - G. Dall'Olmo, A. A. Gitelson, and D. C. Rundquist, Towards a unified approach for remote estimation of chlorophyll- $a$ in both terrestrial vegetation and turbid productive waters, Geoph. Res. Lett. 30 (2003), p. 1938; doi: 10. 1029/2003GL018065.

Dekker, 1993 - A. Dekker, Detection of the optical water quality parameters for eutrophic waters by high resolution remote sensing. Ph. D. thesis, Free University, Amsterdam, The Netherlands, 1993.

Eckert and Parparov, 2006 - W. Eckert and A. Parparov, Feasibility Study for Monitoring Dissolved and Particulate Carbon in Lake Kinneret, IOLR Report T15/06, Israel Oceanographic and Limnological Research, Tabgha (2006).

Field et al., 1998 - C. B. Field, M. J. Behrenfeld, J. T. Randerson, and P. Falkowski, Primary production of the biosphere: integrating terrestrial and oceanic components, Science 281 (1998), pp. 237-240.

Gege and Albert, 2006 - P. Gege and A. Albert, A tool for inverse modeling of spectral measurements in deep and shallow waters. In: L. Richardson and E. LeDrew, Editors, Remote Sensing of Aquatic Coastal Ecosystem Processes: Science and Management Applications, Springer Verlag, New York (2006), pp. 81-109.

Gilerson et al., 2010 • A. A. Gilerson, A. A. Gitelson, J. Zhou, D. Gurlin, W. J. Moses, I. Ioannou, and S. A. Ahmed, Algorithms for remote estimation of chlorophyll-a in coastal and inland waters using red and near-infrared bands, Optics Express 18 (2010), pp. 24109-24125.

Gitelson, 1992 - A. A. Gitelson, The peak near $700 \mathrm{~nm}$ on reflectance spectra of algae and water: relationships of its magnitude and position with chlorophyll concentration, Int. J. Remote Sens. 13 (1992), pp. 3367-3373.

Gitelson et al., 2008 - A. A. Gitelson, G. Dall'Olmo, W. Moses, D. C. Rundquist, T. Barrow, T. R. Fisher, D. Gurlin, and J. Holz, A simple semi-analytical model for remote estimation of chlorophyll-a in turbid waters: validation, Remote Sens. Environ. 112 (2008), pp. 3582-3593.

Gitelson et al., 2009 • A. A. Gitelson, D. Gurlin, W. J. Moses, and T. Barrow, A bio-optical algorithm for the remote estimation of the chlorophyll-a concentration in case 2 waters, Environ. Res. Lett. 4 (2009); doi: 10. 1088/1748-9326/4/4/045003.

Gitelson et al., 2011 - A. A. Gitelson, D. Gurlin, W. J. Moses, and Y. Z. Yacobi, Remote estimation of chlorophyll- $a$ concentration in inland, estuarine, and coastal waters Chapter 18. In: Q. Weng, Editor, Advances in Environmental Remote Sensing: Sensors, Algorithms and Applications, CRC Press, Boca Raton, FL, USA (2011), pp. 449-478.

Gons, 1999 - H. J. Gons, Optical teledetection of chlorophyll $a$ in turbid inland waters, Environ. Sci. Technol. 33 (1999), pp. $1127-1132$.

Gons et al., 2002 • H. J. Gons, M. Rijkeboer, and K. G. Ruddick, A chlorophyll-retrieval algorithm for satellite imagery (medium resolution imaging spectrometer) of inland and coastal waters, J. Plankton Res. 24 (2002), pp. 947-951.

Gons et al., 2005 - H. J. Gons, M. Rijkeboer, and K. G. Ruddick, Effect of a waveband shift on chlorophyll retrieval from MERIS imagery of inland and coastal waters, J. Plankton Res. 27 (2005), pp. 125-127.

Gordon and Morel, 1983 - H. Gordon and A. Morel, Remote Assessment of Ocean Color for Interpretation of Satellite Visible Imagery. A Review, Lecture Notes on Coastal and Estuarine Studies 4, Springer-Verlag (1983).

Gordon et al., 1975 • H. R. Gordon, O. B. Brown, and M. M. Jacobs, Computed relationships between the inherent and apparent optical properties of a flat homogeneous ocean, Appl. Opt. 14 (1975), pp. 417-427.

Han and Rundquist, 1997 - L. Han and D. Rundquist, Comparison of NIR/RED ratio and first derivative of reflectance in estimating algal-chlorophyll concentration: a case study in a turbid reservoir, Remote Sens. Environ. 62 (1997), pp. 253-261.

Herlevi, 2002 - A. Herlevi, A study of scattering, backscattering and a hyperspectral reflectance model for boreal waters, Geophysica 38 (2002), pp. 113-132.

Holm-Hansen et al., 1965 • O. Holm-Hansen, C. J. Lorenzen, R. W. Holmes, and J. D. H. Strickland, Fluorometric determination of chlorophyll, J. Cons. Cons. Int. Explor. Mer. 30 (1965), pp. 3-15.

Hoge et al., 1987 • E. F. Hoge, C. W. Wright, and R. N. Swift, Radiance ratio algorithm wavelengths for remote oceanic chlorophyll determination, Appl. Opt. 26 (1987), pp. 2082-2094.

Joint and Groom, 2000 - I. Joint and S. B. Groom, Estimation of phytoplankton production from space: current status and future potential of satellite remote sensing, J. Exp. Mar. Biol. Ecol. 250 (2000), pp. 233-255.

Kutser et al., 2009 • T. Kutser, M. Hiire, L. Metsamaa, E. Vahtmäe, B. Paavel, and R. Aps, Field measurements of spectral back- 
scattering coefficient of the Baltic Sea and boreal lakes, Boreal Environ. Res. 14 (2009), pp. 305-312.

Le et al., 2009 - C. Le, Y. Li, Y. Zha, D. Sun, C. Huang, and H. Lu, A four-band semi-analytical model for estimating chlorophyll a in highly turbid lakes: the case of Taihu Lake, China, Remote Sens. Environ. 113 (2009), pp. 1175-1182.

Moses et al., 2009a - W. J. Moses, A. A. Gitelson, S. Berdnikov, and V. Povazhnyy, Estimation of chlorophyll-a concentration in case II waters using MODIS and MERIS data-successes and challenges, Environ. Res. Lett. 4 (2009); doi: 10. 1088/1748-9326/4/4/045005.

Moses et al., 2009b - W. J. Moses, A. A. Gitelson, S. Berdnikov, and V. Povazhnyy, Satellite estimation of chlorophyll- $a$ concentration using the red and NIR bands of MERIS - the Azov Sea case study, IEEE Geosci. Remote Sens. Lett. 6 (2009), pp. 845-849.

Ohde and Siegel, $2003 \cdot$ T. Ohde and H. Siegel, Derivation of immersion factors for the hyperspectral Trios radiance sensor, $J$. Opt. A Pure Appl. Opt. 5 (2003), pp. 12-14.

Oki and Yasuoka, 2002 - K. Oki and Y. Yasuoka, Estimation of chlorophyll concentration in lakes and inland seas with a field spectroradiometer above the water surface, Appl. Opt. 41 (2002), pp. 6463-6469.
Pierson and Strombeck, 2000 - D. Pierson and N. Strombeck, A modeling approach to evaluate preliminary remote sensing algorithms: use of water quality data from Swedish great lakes, Geophysica 36 (2000), pp. 177-202.

Schalles, 2006 • J. F. Schalles, Optical remote sensing techniques to estimate phytoplankton chlorophyll a concentrations in coastal waters with varying suspended matter and CDOM concentrations. In: L. Richardson and E. LeDrew, eds., Remote Sensing of Aquatic Coastal Ecosystem Processes: Science and Management Applications, Springer Verlag, New York (2006), pp. 27-79.

Stumpf and Tyler, 1988 - R. P. Stumpf and M. A. Tyler, Satellite detection of bloom and pigment distributions in estuaries, Remote Sens. Environ. 24 (1988), pp. 385-404.

Yacobi, 2006 - Y. Z. Yacobi, Temporal and vertical variation of chlorophyll a concentration, phytoplankton photosynthetic activity and light attenuation in Lake Kinneret: possibilities and limitations for simulation by remote-sensing, J. Plankton Res. 28 (2006), pp. 725-736.

Yacobi et al., 1995 - Y. Z. Yacobi, A. A. Gitelson, and M. Mayo, Remote sensing of chlorophyll in Lake Kinneret using high spectral resolution radiometer and Landsat TM: spectral features of reflectance and algorithm development, J. Plankton Res. 17 (1995), pp. 2155-2173. 